\title{
Integración europea y opinion pública en el auge y declive del comunismo español
}

\section{European integration and public opinion in the rise and fall of the Spanish communism}

\author{
Salvador Forner Muñoz \\ Universidad de Alicante, España \\ salvador.forner@ua.es \\ https://orcid.org/0000-0001-5428-9557 \\ Heidy Cristina Senante Berendes \\ Universidad de Alicante, España \\ hc.senante@ua.es \\ https://orcid.org/0000-0002-9532-8994
}

Recibido: 28/05/2021

Aceptado: 03/12/2021

Cómo citar este artículo: FORNER MUÑOZ, Salvador; SENANTE BERENDES, Heidy Cristina (2022). Integración europea y opinión pública en el auge y declive del comunismo español. Pasado y Memoria. Revista de Historia Contemporánea, (24), pp. 10-41, https://doi.org/10.14198/PASADO2022.24.01

\section{Resumen}

El presente trabajo analiza la posible influencia de las políticas europeas mantenidas por el Partido Comunista de España e Izquierda Unida en los resultados de las distintas coyunturas electorales, sin olvidar que otro tipo de factores, asociados a la integración europea o a la propia evolución ideológica de dicha formación, determinaron también sus resultados electorales. Utilizando fuentes estadísticas, parlamentarias y documentación proveniente de ambas organizaciones, en este artículo se explora la trayectoria electoral del comunismo y la posición adoptada frente a los hitos más significativos del proceso comunitario, mediante el análisis de su discurso político. Se pretende comprobar empíricamente hasta qué punto influyeron la interacción de la 
opinión pública española y las actuaciones y propuestas sobre la integración europea en el auge y el declive electoral del PCE/IU.

Palabras clave: Integración europea; Partido Comunista de España; Izquierda Unida; Política europea; Discurso político; Resultados electorales; Opinión pública.

\begin{abstract}
This paper analyses the influence of the European policies pursued by both the Spanish Communist Party (PCE) and Izquierda Unida (IU) on the electoral results, knowing that such outcomes may have also been shaped by other issues related to those parties own ideological evolution, or to the European project itself. Using statistical and parliamentary sources, as well as documentation drawn from both organizations, the article explores the electoral trajectory of communism and the stand taken, in the face of the most significant milestones of the community process, by analysing their political discourse. The aim is to empirically test to what extent the interaction of both Spanish public opinion and actions and proposals for European integration had an influence on the rise and decline of both PCE and IU.
\end{abstract}

Keywords: European Integration; Spanish Communist Party; Izquierda Unida; European Politics; Political Discourse; Electoral Results; Public Opinion.

Financiación: Este dosier monográfico se enmarca en el proyecto europeo con referencia 610735-EPP-1-ES- EPPPJMO-CHAIR.

\title{
Introducción
}

En los primeros años de la década de 1980 el Partido Comunista de España (PCE) sufrió una aguda crisis política que se tradujo en una gran pérdida de su anterior respaldo electoral. La sustitución de Santiago Carrillo en la secretaría general por un nuevo líder, Gerardo Iglesias, marcó el comienzo de una ligera recuperación del comunismo bajo las siglas de Izquierda Unida, nueva formación política de carácter plural pero plenamente identificada con las políticas y la estrategia del PCE. Durante el liderazgo de Julio Anguita en la década de 1990 se produjo un auge electoral de la opción comunista que abrió incluso la posibilidad, a juicio del nuevo líder, de desbancar la hegemonía del PSOE en el campo de la izquierda. A finales de dicha década el PCE e IU experimentaron, sin embargo, un nuevo declive que se prolongó hasta las elecciones legislativas de 2011.

En este trabajo se analiza la posible influencia de las políticas europeas mantenidas por el PCE/IU sobre sus resultados en las distintas coyunturas electorales, en función de la mayor o menor identificación de la opinión pública 
con el proceso de integración europea. Con la utilización de fuentes estadísticas, parlamentarias y documentación proveniente de ambas organizaciones, el artículo explora la trayectoria electoral del comunismo y la posición adoptada ante los hitos más significativos del proceso comunitario mediante el análisis de su discurso político. Se parte de la hipótesis inicial de que desde el año 1985, con la Adhesión de España a las Comunidades Europeas, se produjo una creciente europeización de la vida política española que afectó a los partidos y a sus bases sociales y electorales. La «europeización», concepto sujeto a debate en cuanto a su alcance y contenido (Olsen, 2002; Conway y Patel, 2010), cobra especial relevancia en su sentido más amplio para el estudio de los efectos de la integración europea sobre aspectos específicos de las políticas nacionales. Con dicho enfoque se presupone que la política europea no es algo externo que se añade a la política nacional sino que es la propia política nacional la que adquiere una dimensión profundamente nueva por efecto del proceso integrador (Cotta, Isernia y Verzichelli, 2005: 7-11; Grande y Hutter, 2016: 110 s.).

Por otra parte, la literatura académica sobre la relación entre la comunicación política y el apoyo público a la integración europea coincide en que las élites políticas nacionales juegan un papel importante en la formación de las actitudes de la opinión pública hacia la Unión Europea (Marks, Wilson, y Ray, 2002: 585-594; Vázquez, 2012: 118-120). Algunas evidencias empíricas sugieren, sin embargo, que esa relación causal no es del todo consistente y puede verse alterada por diversos factores, especialmente las repercusiones económicas de la integración (Anderson, 1998: 569 ss.). Las posiciones de los partidos influyen sin duda en la opinión del electorado pero ese efecto puede variar según los niveles de desacuerdo con otros partidos ideológicamente próximos, así como por la unidad interna del partido o por el grado de apego y fidelidad partidaria del electorado (Ray, 2003: 978 ss.). En el sentido inverso, puede plantearse también la hipótesis de que, en determinadas coyunturas, es la propia evolución de la opinión pública la que puede moldear el discurso político de los distintos partidos y que su adaptación o no a las variaciones experimentadas por aquella contribuye a explicar algunos de los cambios en su respaldo electoral (Cotta, 2005: 48 ss.).

Partiendo de estas hipótesis teóricas, en el presente artículo se pretende comprobar empíricamente hasta qué punto influyeron las interacciones entre el estado de la opinión pública española y las actuaciones y propuestas sobre la integración europea en el auge y declive electoral del PCE/IU. El trabajo se propone también dilucidar qué otro tipo de factores asociados a la integración o a la propia evolución ideológica de dicha formación política influyeron en 
su trayectoria electoral. Con relación a este último aspecto el trabajo abre en sus conclusiones una interrogación sobre la adecuación o no del concepto y el término de euroescepticismo en referencia al discurso sobre la integración europea del PCE/IU desde la aprobación del Tratado de Maastricht.

\section{En torno a la Adhesión: europeísmo y anti atlantismo}

Ante la Adhesión de España a las Comunidades Europeas el nuevo secretario general del PCE, Gerardo Iglesias, apostaba por la plena incorporación de España como expresión de la voluntad del comunismo español de «contribuir a edificar la Europa de los pueblos». Esa vocación pro-europea se orientaba hacia la posible configuración de un nuevo orden democrático internacional en el que Europa podría jugar un destacado papel. Según Iglesias, en referencia a la OTAN, la autonomía respecto a Estados Unidos permitiría a Europa jugar un papel internacional de enorme influencia. «Por el contrario, Europa no encontrará ninguna ventaja por el camino de la creciente subordinación a los Estados Unidos y contribuirá con ello a la lógica de la pugna entre las grandes potencias por el control del planeta» (Iglesias, 1984: 61).

El PCE se esforzaba en diferenciar en su discurso sobre Europa la incorporación española a las Comunidades Europeas de la permanencia de España en la Alianza Atlántica. La OTAN era considerada como un mero instrumento del imperialismo norteamericano y significaba para el PCE una merma de la soberanía nacional y de la capacidad del pueblo español de ser plenamente dueño de sus destinos. Por el contrario, la actitud favorable hacia la CEE propició la aprobación por los diputados comunistas de la ratificación del Tratado de Adhesión en 1985. El PCE consideraba la pertenencia de España a la CEE, en palabras de su portavoz parlamentario Pérez Royo, no solo «como una necesidad derivada del propio desarrollo de la economía española» sino también «como un paso importante para la construcción de una Europa unida políticamente» ${ }^{1}$.

El relato favorable a la incorporación de España a la CEE por parte del PCE coincidía con la opinión pública española respecto a la asociación entre europeísmo y democracia, y con la imagen de la Europa comunitaria como un referente de modernización y de progreso económico y social (Avilés, 2004: 418). España era, de entre los Estados miembros no fundadores que en 1985 iban a completar la Europa de los doce, el país con mayor identificación afectiva con la Comunidad Europea. Pero la opinión pública española era también

1. Diario de Sesiones del Congreso (DSC): 25-06-1985, p. 10210. 
mayoritariamente contraria a la pertenencia de España a la OTAN y a la existencia de los bloques militares. Entre 1978 y 1983 las opiniones favorables al ingreso o la permanencia de España en la Alianza Atlántica habían descendido desde el 27 por 100 al 13 por 100 mientras que las desfavorables aumentaban espectacularmente desde el 15 por 100 al 57 por 100. Por lo que se refiere a la relación entre la incorporación a la Comunidad Europea y la permanencia en la OTAN, la encuesta del Centro de Investigaciones Sociológicas (CIS) de junio de 1983 mostraba la no vinculación entre ambas organizaciones por parte de la opinión pública: un 71 por 100 de los encuestados manifestaban que su opinión desfavorable sobre la OTAN no cambiaría ante el supuesto de una posible incorporación de España a la CEE. Esa actitud se hacía más pronunciada en el caso de los votantes de izquierda (74 por 100) y de extrema izquierda (88 por 100$)^{2}$.

Cuadro 1. Actitudes ante la Comunidad Europea (porcentaje medio, 1982-1985)

\begin{tabular}{|l|c|c|c|}
\cline { 2 - 4 } \multicolumn{1}{c|}{} & $\begin{array}{c}\text { La pertenencia a la } \\
\text { CEE es beneficiosa } \\
\text { para mi país }\end{array}$ & $\begin{array}{c}\text { La pertenencia a la } \\
\text { CEE no es beneficiosa } \\
\text { para mi país }\end{array}$ & $\begin{array}{c}\text { Estoy a favor de los } \\
\text { esfuerzos para la } \\
\text { unificación de Europa } \\
\text { occidental }\end{array}$ \\
\hline España & $67 \%$ & $10 \%$ & $90 \%$ \\
\hline Portugal & $53 \%$ & $17 \%$ & $85 \%$ \\
\hline Irlanda & $50 \%$ & $22 \%$ & $80 \%$ \\
\hline Grecia & $47 \%$ & $18 \%$ & $79 \%$ \\
\hline Dinamarca & $37 \%$ & $31 \%$ & $48 \%$ \\
\hline Reino Unido & $35 \%$ & $35 \%$ & $77 \%$ \\
\hline
\end{tabular}

Fuente: Eurobarometer. The Dynamics of European Public Opinion, MACMILLAN, London, 1991, p. 8.

El referéndum sobre la permanencia de España en la OTAN convocado por el Gobierno de Felipe González en 1986 daba al PCE la oportunidad de ofrecer un discurso alternativo que, en aquellos momentos, al insistir en la disociación entre atlantismo y europeísmo, parecía sintonizar plenamente con un sector mayoritario de la opinión pública. El referéndum se saldó, sin embargo, con una victoria de los partidarios de la permanencia manifestando un cambio de

2. La actitud ante la OTAN y los boques militares en: CIS: La opinión pública española ante la OTAN (http://www.reis.cis.es/REIS/PDF/REIS_022_12.pdf). 
tendencia de la opinión pública, que ya había comenzado meses antes y que remite a diversos factores relacionados con el viraje occidentalista de Felipe González y su empeño en remarcar el vínculo europeo del atlantismo (Mateos, 2016: 67).

A pesar de que la disociación entre la apuesta por la integración y el rechazo al atlantismo no había dado al PCE el resultado esperado, la existencia de un amplio sector de la opinión pública contrario a la permanencia de España en la OTAN - un 39,8 por 100 de los votos del referéndum- podía servir para capitalizar el desgaste que el viraje del socialismo en la «cuestión atlántica» iba presuntamente a provocar en parte de su electorado. La estrategia del PCE, tras el revés sufrido en el referéndum como principal fuerza política impulsora del NO, se orientó hacia la consolidación de una coalición unitaria, Izquierda Unida (IU), plenamente identificada con las movilizaciones anti-OTAN que, con ocasión del referéndum, habían sido precisamente la fragua de dicha coalición. Como fuerza política mayoritaria, el PCE trasladó al programa electoral de IU su posición favorable a la integración europea y contraria al atlantismo, pero los resultados de las elecciones legislativas de 1986 fueron bastante decepcionantes para esa nueva coalición que obtuvo solo siete escaños, cuatro de los cuales pertenecían al PCE. La supuesta capitalización electoral de las movilizaciones anti-OTAN no se producía y, por el contrario, era el PSOE el que revalidaba la mayoría absoluta de 1982 rentabilizando a su favor el impacto en la opinión pública de la incorporación de España a la Europa comunitaria en 1985.

Durante los años que siguieron a la Adhesión a la CEE la política europea del PCE siguió marcada por el rechazo del atlantismo y el respaldo al proceso comunitario. La incorporación de España a las Comunidades había coincidido con la aprobación del Acta Única Europea, cuya ratificación parlamentaria fue apoyada por todos los diputados de Izquierda Unida. Dicho tratado dio inicio a un proceso de debates y reformas que culminó seis años más tarde con la aprobación del Tratado de la Unión Europea. El impulsor de dicho proceso fue el presidente de la Comisión Europea, Jacques Delors, quien propuso a los distintos gobiernos europeos avanzar en diversos aspectos de la integración hacia metas de unidad política. Uno de esos avances se refería al futuro establecimiento de una moneda común lo que requería previamente una liberalización completa de los movimientos de capitales. Dicho requisito no suponía en realidad otra cosa que la culminación del mercado común según se había establecido en el Tratado de la CEE de 1957. El nuevo tratado estableció también una serie de reformas que reforzaban el papel del Parlamento Europeo, 
ampliaban el ámbito de las decisiones adoptadas por mayoría cualificada en el Consejo y consagraban el concepto de cohesión económica y social.

El apoyo del PCE/IU a la ratificación del Acta Única estaba en consonancia con sus posiciones favorables a la integración mantenidas hasta entonces que propugnaban la necesidad de avances hacia la unidad política de Europa. De alguna forma, aunque tímidamente, el nuevo tratado se orientaba en tal sentido si bien, por las características de la integración, no se superaba, según IU, el denominado "déficit democrático» en el funcionamiento institucional de la Comunidad Europea. Los aspectos críticos de la visión comunista de la CEE en los años inmediatamente posteriores a la Adhesión no afectaban, sin embargo, al núcleo esencial del proceso ni impedían una total identificación con este, que se acompañaba, además, de una convicción sobre la necesidad para España de estar plenamente incorporada a dicho proceso. Era en las propuestas para el futuro de una Europa unida en el marco internacional donde se mantenía la divergencia entre la apuesta por la integración económica y política de Europa occidental y la denuncia de lo que, en línea con el discurso anti atlantista, se consideraba «un pensamiento europeísta de corte conformista y sumiso respecto de las estrategias americanas» (Iglesias, 1986: 5-7). Pero, tal y como se había comprobado en las elecciones de 1986, la opinión pública española no era especialmente receptiva al «europeísmo anti atlantista» con el que el PCE intentaba ofrecer un discurso alternativo al del socialismo.

En la segunda mitad de los ochenta y primeros noventa el contexto internacional y europeo experimentó, sin embargo, una serie de cambios de profundo calado que iban a diluir progresivamente el cleavage que en el seno de la izquierda española se daba en torno a la existencia de los bloques y el bipolarismo. La llegada al poder de Gorbachov en 1985 supuso el inicio de una distensión entre los bloques que finalmente llevó a la disolución oficial del Pacto de Varsovia el 1 de julio de 1991. Gorbachov impulsó también el proyecto de la «casa común europea» lo que abría la posibilidad de cooperación de la CEE con el Consejo de Ayuda Económica Mutua (CAME) de los países del bloque del Este. La cuestión del anti atlantismo iba a ir perdiendo, como consecuencia de dichos cambios, transcendencia ideológica en el discurso europeísta del PCE y haciendo más idónea para su sintonía con la opinión pública la apuesta por un futuro de unidad europea «desde el Atlántico a los Urales» impulsado por la propia Comunidad Europea ${ }^{3}$.

3. AHPCE: Un proyecto de izquierda para una Europa de progreso. Conferencia nacional del Partido Comunista de España, Madrid, 21 y 22 de enero de 1989, p. 4. 
Desde la perspectiva económica, el PCE reforzó también durante esos años su identificación con el proceso de integración tal y como se había configurado en el Acta Única Europea. La realización del mercado interior era considerada beneficiosa desde un doble punto de vista. En primer lugar porque servía para «dotar de una base económica al proyecto político de unidad europea». En segundo lugar por su efecto positivo en la mejora de la calidad de vida de la población trabajadora «en su dimensión de consumidores» ${ }^{4}$. En las elecciones europeas celebradas en junio de 1989 Izquierda Unida presentó un programa electoral acorde con dichos planteamientos y en el que se insistía en la necesidad de una completa culminación del «mercado interior único y de la cohesión económica y social» tal como se había establecido en el Acta Única. La propuesta electoral abogaba también por la «coordinación de las políticas económicas de los diferentes Estados con el fin de favorecer e impulsar un crecimiento equilibrado», lo cual representaba una conformidad inicial con lo que posteriormente iban a ser las políticas de convergencia. El programa electoral de IU se pronunciaba también por el «reforzamiento del Sistema Monetario Europeo» abogando por «el ingreso de España en el mismo» ${ }^{5}$. El resultado de dichas elecciones marcó el comienzo de una recuperación electoral de Izquierda Unida, que obtuvo el 6 por 100 de los votos y 4 escaños en el Parlamento Europeo. Meses después, en las elecciones legislativas de octubre de 1989 IU duplicó prácticamente el porcentaje de voto obtenido en las legislativas de 1986 pasando de 7 a 17 escaños en el Congreso de los Diputados.

¿Hasta qué punto influyó la «cuestión europea» en ese significativo ascenso electoral? La transferencia de voto en dichas elecciones indica que la mayor parte de nuevos votantes de Izquierda Unida eran antiguos votantes del PSOE. Es decir que la suavización de la radicalidad anti-occidental de años anteriores, motivada en gran parte por el nuevo contexto internacional, parecía tener un efecto más beneficioso para la competencia electoral en el campo de la izquierda que el mantenimiento de dicha radicalidad durante los años de la Adhesión y del referéndum sobre la OTAN. Lo mismo podría decirse del más explícito apoyo a la integración europea que se observa durante la segunda mitad de la década de los ochenta -especialmente tras la aprobación del Acta Única- como estrategia para lograr superar el «déficit europeísta» del

4. Ibídem, p. 7.

5. Izquierda Unida. Europa'89. Propuestas, p. 4. 
comunismo en comparación con otras formaciones políticas. Esa era la conclusión a la que llegaba Francisco Palero, responsable de la política internacional del PCE durante estos años, al referirse a la percepción del comunismo como opción política contraria a la CEE. Dicha percepción habría dejado, a pesar de algunas excepciones, «toda la iniciativa [en el proceso de integración] a las fuerzas socialdemócratas y conservadoras» e influido negativamente en la opinión pública motivando la escasa implantación de los partidos comunistas en la mayoría de los países comunitarios (Palero, 1990: 41).

La atenuación del anti-atlantismo y la intensificación del europeísmo en el discurso político del PCE parecían, así pues, acomodarse al estado de una opinión pública que experimentaba un creciente apoyo a la integración por las consecuencias económicas de esta. Entre 1986 y 1990 el Producto Interior Bruto (PIB) español creció a una media del 4,8 por 100 anual, crecimiento muy superior al de los cinco años anteriores a la entrada en la CEE (1981-1985) en los que el crecimiento medio fue tan solo del 1,8 por 100. El comercio entre España y el resto de países comunitarios creció también muy significativamente durante los cinco años siguientes a la Adhesión al pasarse de un equivalente de 30.200 millones a 69.200 millones de euros. En el momento de la Adhesión las cifras de desempleo en España alcanzaban un porcentaje próximo al 22 por 100 sobre el conjunto de la población activa pero dicho porcentaje se fue reduciendo hasta el año 1991 en el que se experimentó un descenso al 16 por 100 de la tasa de paro. En paralelo a esa mejoría económica, la percepción de los beneficios que podía estar originando la incorporación a Europa subió de forma espectacular entre 1986 y 1991 disminuyendo significativamente las opiniones contrarias hasta ese mismo año (gráfico 1). Más allá de la percepción beneficiosa de dichos efectos, la identificación afectiva con la integración europea aumentó también significativamente tras la Adhesión, llegándose a alcanzar entre 1988 y 1991 porcentajes superiores al 80 por 100 de opiniones favorables y menos del 10 por 100 de opiniones desfavorables durante esos mismos años ${ }^{6}$.

6. Eurobarómetros de primavera y otoño, años correspondientes. 
Grafico 1. Identificación utilitaria con la CE/UE

\section{¿Considera que la pertenencia a la CE/UE está teniendo efectos beneficiosos para España?}

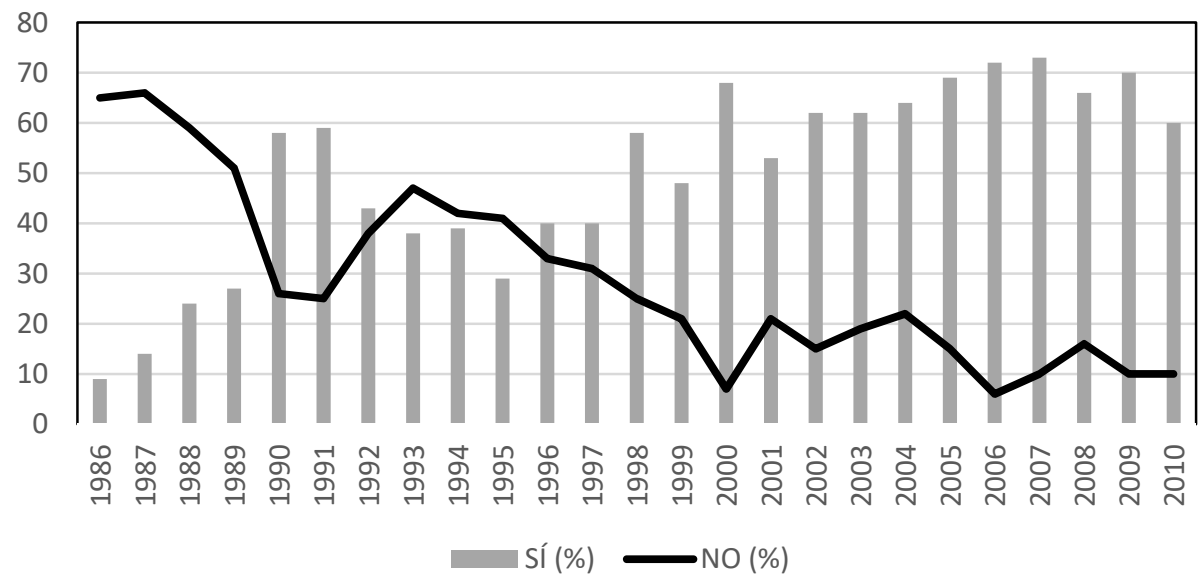

Fuente: Eurobarómetros de primavera, años correspondientes.

De la mayor aproximación de la política internacional y europea del comunismo a posiciones en gran parte similares a las del PSOE no cabe deducir, desde luego, que esa fuera la única posible influencia en el aumento del respaldo electoral de IU en 1989. Correlación no implica causalidad y, sin duda, otros factores están asociados también a ese aumento. La propia consolidación de Izquierda Unida al ampliar, y en parte diluir, la oferta electoral del comunismo pudo ser también una de las causas de ese avance electoral (Bosco y Gaspar, 2001: 346-349), que contrastaba espectacularmente con lo que estaba sucediendo en el resto de partidos comunistas de Europa occidental (Forner y Senante, 2015: 305-316). El desgaste socialista por la gestión de las consecuencias sociales y laborales de la integración -reconversiones industriales y reforma del mercado laboral- puede ser también un factor explicativo de la captación de votos por parte de IU en los sectores obreros. En diciembre de 1988 los dos sindicatos mayoritarios, Comisiones Obreras y UGT, convocaron con gran éxito una huelga general que mostraba el desencuentro que se estaba produciendo entre el gobierno de González y una parte importante de su base social y electoral. No hay duda, por último, de que otro factor influyente en el auge del PCE/IU a fínales de la década de 1980 fue el cambio de liderazgo ocurrido en el XII Congreso con el acceso a la secretaría general de Julio Anguita. 


\section{Anguita, Maastricht, y la salida del «bucle europeísta»}

La personalidad de Anguita se alejaba de los rasgos habituales de la dirigencia de los partidos comunistas, estrechamente ligada por lo general a la permanencia durante largos años en las estructuras internas del aparato partidario. Anguita pertenecía, por el contrario, a la joven generación que en la primera mitad de los años setenta, todavía en la clandestinidad, había iniciado su militancia en el PCE engrosando las filas de las denominadas «fuerzas de la cultura». Maestro de profesión, nunca abandonó en sus intervenciones y escritos un cierto tono pedagógico y moralizante que trascendía la habitual vulgata marxista de otros dirigentes comunistas. Su acceso a la secretaría general tenía lugar tras una dilatada gestión como alcalde de Córdoba, la única alcaldía comunista de una capital de provincia tras las elecciones de 1979, cuyo cargo había revalidado exitosamente con una mayoría absoluta en las elecciones de 1983. A estos atributos se unía un halo de ejemplaridad ética y austeridad personal, que lo acompañó a lo largo de toda su vida ${ }^{7}$ y que, en su conjunto, como puede verse en el cuadro $n .^{\circ} 2$, motivaron un aumento creciente de su popularidad convirtiéndolo en el líder político mejor valorado por la opinión pública española entre 1992 y 1994. Ideológicamente, sin embargo, el nuevo líder del PCE y de Izquierda Unida no sintonizaba plenamente con la evolución experimentada por el PCE en su política europea ni con los nuevos vientos del comunismo en la Unión Soviética impulsados por Gorbachov. En buena medida, los planteamientos de Anguita se alejaban de las posiciones renovadoras y significaban una vuelta atrás, a tiempos incluso anteriores a la etapa eurocomunista del PCE. Como consecuencia de ello, tras el derrumbe del Muro de Berlín y el comienzo de las transiciones a la democracia en los países del Este, la respuesta del PCE, bajo la nueva dirección de Anguita, coincidía con la de partidos comunistas como el francés y el portugués (Bell, 1996: 228 ss.) que, a diferencia del partido comunista italiano, mantuvieron sus señas de identidad comunista y el rechazo a cualquier identificación con la socialdemocracia.

Como expone Emanuele Treglia (2019: 127-155) en su análisis sobre la evolución del discurso del comunismo español entre 1989 y 1992, el viraje hacia la izquierda propiciado por Anguita se basaba en una nueva consideración del orden mundial que, tras la desaparición del bipolarismo, habría dado paso a la completa hegemonía del gran capital y del imperialismo americano. En ese contexto internacional el PCE reafirmaba su seña de identidad comunista reforzando sus relaciones con partidos como el francés (PCF) y el portugués

7. Su trayectoria vital y política en: Anguita y Flor (2017); Anguita y Andrade (2015); Anguita y Monedero (2013). 
(PCP) y criticando abiertamente el cambio ideológico del partido comunista italiano por su evolución hacia la socialdemocracia ${ }^{8}$. Esa crítica se extendía también retrospectivamente a las reformas de Gorbachov por haber truncado el protagonismo internacional de la Unión Soviética y haber propiciado su deslizamiento hacia un puro sistema capitalista (Treglia, 2019: 140). Por el contrario, se estrechaban las relaciones con países como Corea del Norte, la República Popular China o la Cuba de Castro, donde seguían vigentes los regímenes comunistas, y se devaluaba la democracia parlamentaria de corte occidental (Treglia: 2019: 145 y 146).

La deriva antioccidental del PCE y la reafirmación teleológica del comunismo como «culminación y superación de todos los derechos humanos» (Anguita, 1990: 5) no afectó, hasta la aprobación del Tratado de Maastricht, a las posiciones sobre la integración europea mantenidas desde años atrás. En diciembre de 1991, pocos días antes de la disolución de la Unión Soviética se celebró el XIII Congreso del PCE. Las resoluciones aprobadas en este valoraban muy favorablemente el proceso de integración europea, a pesar de su «carácter limitado e insuficiente» y se apostaba por el desarrollo de un proceso político que «desemboque en la construcción de una entidad política de ámbito comunitario y de carácter supranacional $»^{9}$. El XIII Congreso se pronunciaba también sobre los debates que se estaban produciendo acerca del alcance y contenido del proceso unitario europeo, en especial en lo relativo a la política exterior y de seguridad. No deja de resultar extraño, sin embargo, que la referencia a esos debates obviase una cuestión de tanta relevancia como la unión económica y monetaria, quizá debido a una latente división entre las posiciones de Anguita y las del sector renovador que afloraría tras dicho Congreso. El proyecto de unificación monetaria se había plasmado años atrás en el Acta Única Europea, tratado que el PCE, como ya se ha dicho, había apoyado en la ratificación parlamentaria de 1987. Pero la cuestión monetaria, obviada por el momento, iba a ser precisamente la que iba a provocar meses después del XIII Congreso un cambio radical en el discurso europeísta mantenido hasta entonces por el comunismo español.

Más allá de otros contenidos y de avances en cuestiones políticas y sociales, la unión monetaria constituía el núcleo duro del nuevo tratado, aprobado en Maastricht en febrero de 1992, que daba origen a la Unión Europea. La entrada en vigor del tratado exigía la ratificación posterior de los doce Estados

8. No obstante, aunque minoritarias, hubo también posiciones favorables a una refundación del PCE en una nueva formación de izquierda que se alejase de la ideología comunista (Treglia, 2019: 140-145).

9. Manifiesto del PCE para la Izquierda. Documentos aprobados en el XIII Congreso del PCE. Utopías. Nuestra Bandera, 203/204, 118-201. 
miembros que en España iba a realizarse por vía parlamentaria y fue en ese momento cuando se explicitaron abiertamente las divergencias en torno a este y la negativa de Anguita a dar su apoyo al mismo. Diversos economistas y politólogos vinculados o próximos al PCE o IU, como Manuel Monereo, Jesús Albarracín, Pedro Montes y Salvador Jové, proporcionaron a Anguita una base argumental sobre la que sustentar dicha negativa (Monereo, 2010). Sus críticas al Tratado de la Unión Europea (TUE) coincidían, con ligeros matices, en considerarlo un nuevo paso en el proceso de integración que únicamente reforzaba la lógica capitalista del mercado único. Pero esa lógica era para ellos, en definitiva, la que había marcado todo el proceso de integración desde sus inicios mediante la construcción de un espacio económico supranacional en beneficio de las multinacionales como «forma organizativa hegemónica del gran capital»:

El nacimiento del Mercado Común y su posterior evolución han estado dominados por las necesidades del gran capital vinculado a los monopolios, oligopolios y multinacionales, que en las fronteras nacionales encontraban límites a la expansión y concentración exigidas por las leyes del desarrollo capitalista (Albarracín y Montes, 2012: 57-60).

La moneda única planteaba también, según las opiniones contrarias a esta, una serie de problemas derivados de las exigencias para el acceso a la misma. Los criterios de convergencia relativos al control de la inflación, el déficit, la deuda y la confluencia de los tipos de interés iban a provocar, supuestamente, una aguda recesión económica en los países menos desarrollados (Martín Seco, 1992: 17) $\mathrm{y}$ «un asalto al Estado de bienestar y a las condiciones de vida y laborales de los trabajadores» que se impondría utilizando el pretexto del europeísmo:

«Los requisitos de Maastricht obligarán a todos los Gobiernos a endurecer las políticas económicas, lo que les brinda un pretexto para aplicar políticas rigurosas y anti-sociales. El nuestro no ha tardado en transmitir el mensaje y poner manos a la obra. Con una actitud bastante acrítica y de cierto papanatismo el Gobierno pretende imponer una política económica firme que permita a nuestro país cumplir y, si es posible, rebasar las condiciones de Maastricht» (Albarracín y Montes, 1992: 106).

La nueva institución creada por el tratado, el Banco Central Europeo, era asimismo contemplada muy negativamente. La independencia del futuro Banco respecto a los Gobiernos de los países que accediesen a la moneda única y su función como garante de la estabilidad monetaria mediante el control de la inflación constituían, a juicio de los críticos de Maastricht, un serio impedimento para la soberanía económica de los Estados ya que «no podrán emitir moneda, no podrán incurrir en déficits presupuestarios, no tendrán autonomía 
para las políticas monetaria y fiscal», lo que «provocará que las desigualdades que produce el mercado tengan efectos acumulativos para un progresivo empobrecimiento» de los países menos desarrollados (Albarracín y Montes, 1992: 75-78). La asunción por parte de Anguita de los argumentos contrarios al Tratado de Maastricht originó un desencuentro en el seno de Izquierda Unida que dio origen a una división del grupo parlamentario en el voto de ratificación del tratado por el Congreso de los Diputados ${ }^{10}$.

El Tratado de Maastricht entró en vigor en noviembre de 1993, abriendo una etapa de la integración presidida por las políticas de convergencia para el acceso a la moneda única. Al igual que había ocurrido en 1985 con la Adhesión, Felipe González había tenido un destacado protagonismo en la aprobación del nuevo tratado. Su sintonía con algunos de los líderes europeos de aquellos años, como Kohl o Mitterrand, y su decidido apoyo al denominado eje franco-alemán le habían permitido influir decisivamente en algunos logros del tratado como era el caso de la ciudadanía europea, especialmente relevante para España dado el alto número de emigrantes en países comunitarios. A diferencia, sin embargo, de lo ocurrido siete años antes, la capitalización política de ese protagonismo se vio contrarrestada por una evolución de la economía que había comenzado a deteriorarse de una forma acelerada a partir del año 1991. Desde esa fecha toda la Europa comunitaria se estaba resintiendo de las dificultades de Alemania tras la reunificación. El lamentable estado de la economía y de las infraestructuras de la antigua República Democrática Alemana estaban obligando a un esfuerzo de considerables proporciones que originó un cambio en las prioridades de la política económica de la República Federal muy perjudicial para el resto de países comunitarios. En el caso de España se produjo desde el año 1990 una caída en el crecimiento anual del Producto Interior Bruto (PIB) que alcanzó su cota más baja en 1993 con un decrecimiento del 1 por 100 mientras que en ese mismo año el déficit público aumento hasta un 7 por 100 sobre el PIB. La crisis económica se tradujo también en un aumento espectacular del paro que alcanzó en 1993 un porcentaje del 24,5 por 100 sobre la población activa, la cifra más alta hasta ese momento de todo el registro histórico de dicho indicador. La evolución de la opinión pública experimentó durante esos años un significativo deterioro en la percepción del proceso de integración, tanto desde el punto de vista afectivo como desde el punto de vista utilitario. Entre 1993 y 1995 (Vid. gráfico 1) las opiniones desfavorables sobre los beneficios

10. Sobre las divergencias en torno al TUE: Heywood (1994: 71 ss.); Treglia (2019: 147 ss.); Forner y Senante (2019, 353 ss.). 
para España de la pertenencia a la UE superaron en porcentaje a las que consideraban beneficiosa dicha pertenencia.

La inflexión de la opinión pública respecto al proceso de integración sintonizaba en estos momentos, así pues, con el viraje del discurso europeísta del PCE desde la aprobación del Tratado de Maastricht. En las elecciones legislativas de 1993 IU incrementaba su respaldo electoral en casi 400.000 votos -lo que suponía un aumento de más del 21 por 100 sobre los obtenidos en 1989mientras que el PSOE, que ya había perdido la mayoría absoluta en las elecciones de ese último año, veía reducida ahora su representación parlamentaria hasta los 159 escaños. Iba a ser, no obstante, en las elecciones al Parlamento Europeo de 1994 cuando la hegemonía electoral del PSOE en el campo de la izquierda parecía iniciar un declive en beneficio de la formación política liderada por Anguita. En dichas elecciones IU obtuvo casi un 14 por 100 de los votos y 9 eurodiputados, un aumento espectacular si se tiene en cuenta que en las anteriores elecciones europeas había obtenido tan solo el 6 por 100 de los votos y 4 eurodiputados. Esa percepción de auge de la oferta electoral comunista se acrecentaba con el resultado de las elecciones autonómicas en Andalucía, celebradas conjuntamente con las elecciones al Parlamento europeo en ese mismo año. Izquierda Unida se había acercado al 20 por 100 del voto en dichas elecciones mientras que el PSOE había cosechado el peor resultado hasta entonces en el que constituía su auténtico feudo electoral desde 1982.

La centrifugación del voto socialista a derecha e izquierda y las expectativas generadas por los avances electorales de IU hicieron concebir a Anguita la posibilidad de desbancar la hegemonía mantenida hasta entonces por el PSOE en el campo político e ideológico de la izquierda española. Dicha estrategia se veía favorecida por la gravedad de la crisis económica y por una corrupción política de grandes proporciones en la administración socialista que llevó incluso a un acercamiento táctico de Anguita al Partido Popular (PP) para una posible moción de censura a Felipe González"11. La "cuestión europea» constituía a tal efecto un instrumento idóneo para la erosión del Gobierno socialista. Situados el PSOE y el PP en la misma «orilla» europeísta identificada con los postulados de Maastricht, la creciente desafección de la opinión pública con las consecuencias económicas que, supuestamente, estaba provocando la convergencia hacia la moneda única podía ser rentabilizada por Izquierda Unida como única fuerza política contraria a dicha convergencia, es decir, la situada en la otra «orilla». El liderazgo de Anguita constituía también otro factor que permitía

11. Las cartas cruzadas entre Anguita y Aznar sobre dicha cuestión en enero de 1995 en $A B C, 19-01-2015$. https://www.abc.es/espana/20150118/abci-aznar-anguita-1995nada-201501172056.html. 
alimentar las expectativas del sorpasso al PSOE. Su valoración por parte de la opinión pública (Cuadro 2) se acrecentó, como ya se ha dicho, durante la primera mitad de la década de 1990 al contrario de lo ocurrido con Felipe González durante el mismo período.

Cuadro 2. Valoración de líderes políticos entre 1990 y 1999 en una escala del 0 al 10

\begin{tabular}{|l|c|c|c|c|c|c|}
\cline { 2 - 7 } \multicolumn{1}{c|}{} & $1990(\mathrm{D})$ & $1992(\mathrm{~S})$ & $1994(\mathrm{Ju})$ & $1996(\mathrm{O})$ & $1998(\mathrm{O})$ & $1999(\mathrm{O})$ \\
\hline Julio Anguita & 4,47 & 5,12 & 5,93 & 4,18 & 3,77 & 3,40 \\
\hline José M. ${ }^{a}$ Aznar & 4,09 & 4,69 & 4,70 & 4,49 & 4,91 & 4,76 \\
\hline $\begin{array}{l}\text { Felipe González / } \\
\text { Joaquín Almunia }\end{array}$ & 5,41 & 5,26 & 4,77 & 5,34 & 4,97 & 4,54 \\
\hline
\end{tabular}

Fuente: CIS, Barómetros de opinión, años correspondientes.

La estrategia del sorpasso y de las «dos orillas» comenzó, sin embargo, a estancarse desde el año 1996. Ese estancamiento se reflejaba en los resultados de las elecciones legislativas del mes de marzo en las que la pérdida de la mayoría parlamentaria del PSOE daba paso al Gobierno conservador de José María Aznar. Es cierto que IU, como sucesora del PCE, alcanzaba los mejores resultados en unas elecciones legislativas desde el año 1979 pero, con un 10,54 por 100 de los votos, sus expectativas quedaban muy lejos de poder sobrepasar en el futuro a un PSOE que iniciaba su labor en la oposición con un sólido respaldo del 37,63 por 100. Es decir que la estrategia de desgaste del PSOE mediante la identificación de su política económica con la de la derecha durante la etapa de convergencia hacia la moneda única no solo no daba los resultados esperados sino que se traducía en un triunfo del PP cuyo programa abogaba precisamente por un más estricto cumplimiento de las políticas de convergencia para acceder a la Unión Monetaria (Forner y Senante, 1919: 359).

Desde 1996 en adelante los planteamientos del PCE e IU sobre el acceso a la moneda única siguieron marcados por un rechazo frontal que llegaba incluso a adquirir tonos catastrofistas al ser considerado este como un «camino hacia el abismo» que agravaría los «desequilibrios económicos, sociales y ambientales» y supondría «una vuelta paulatina a las condiciones laborales del siglo XIX ${ }^{12}$. Dicha visión se acompañaba de la confianza en un supuesto deterioro ante la opinión pública del «mito de la construcción europea» que se estaría

12. Contra la Europa de Maastricht y la globalización económica. Declaración política. Utopias. Nuestra Bandera, 171, 1997, p. 64. 
desmoronando «progresivamente a los ojos de amplios sectores sociales, especialmente de aquellos afectados por el despliegue del modelo»:

«Esta creciente quiebra de la imagen del «proyecto europeo» se verá incentivada, pensamos, como consecuencia de la exigencia del capital al poder político (en la actualidad al nuevo gobierno del PP) de acceder a costa de lo que sea a la moneda única. [...] Y es de esperar que entremos, quizás, en una etapa de una mayor disposición para que prospere el pensamiento crítico, y se promueva una mayor capacidad de movilización social que permita decir basta ya a toda esta demencia» ${ }^{13}$.

En consonancia con dichos planteamientos, IU votó en contra de un nuevo tratado comunitario, el de Ámsterdam, que revisaba algunos aspectos del Tratado de Maastricht. La enmienda a la totalidad de la ratificación del tratado seguía insistiendo en las consecuencias perjudiciales para la economía española de las políticas de convergencia por sus «efectos depresivos» que contribuían a «agravar el problema del paro en vez de resolverlo». Según el portavoz parlamentario de IU, la unión monetaria no se había «completado con una verdadera dimensión económica y social porque ambos objetivos, tal y como están planteados, son incompatibles». La previsión de IU era que el tratado distanciaría todavía más a la opinión pública del proceso de integración trasladando a la misma una percepción de «antagonismo entre la moneda única y el empleo» ${ }^{14}$.

La opinión publica estaba evolucionando, sin embargo, desde 1996 en sentido contrario, es decir, de forma cada vez más favorable a la Unión Europea y a la futura moneda única. Esa evolución era paralela a una progresiva recuperación económica que se había iniciado ya en los últimos meses del Gobierno socialista tras algunos cambios en la política económica, introducidos por el ministro Pedro Solbes para intentar cumplir los criterios de convergencia. El PIB había empezado a remontar desde 1994 alcanzando entre 1997 y 2000 crecimientos anuales superiores al 4 por 100. Desde 1996 España fue acercándose a los requisitos establecidos en Maastricht para el acceso a la moneda única. La disminución de la inflación, del déficit, de los tipos de interés y de la deuda colocó al país en condiciones de superar los criterios de convergencia. La disciplina presupuestaria exigida para cumplir dichos criterios no se traducía en un desmantelamiento del Estado de bienestar ni tampoco en un deterioro del empleo sino todo lo contrario ${ }^{15}$. Desde 1995 se había ido produciendo una

13. Ibídem, p. 70.

14. Intervención del portavoz del grupo parlamentario federal de IU, Navas Amores. DSC, $n^{\circ} 171,1998$, pp. $9202-9204$.

15. Entre 1996 y 2000 el gasto presupuestado en Educación y Sanidad se incrementó en más de un 28 por 100. INE. Estadísticas históricas. https://www.ine.es/dyngs/IOE/es/ inicioHist.htm. 
espectacular disminución del porcentaje de parados sobre la población activa pasando del 24,55 por 100 en 1994 al 10,94 por 100 en 2001, año que marcó también un mínimo en el paro registrado desde 1981.

Poco antes de la constitución de la unión monetaria España era uno de los países de la UE con opinión pública más favorable a la introducción de la moneda única. También era ampliamente mayoritario en aquellos momentos el respaldo en general de la ciudadanía a la Unión Europea sin que existieran excesivas divergencias al respecto en función de la identificación partidaria. Es cierto que en el caso del electorado de IU se daba un mayor porcentaje de actitudes contrarias pero el porcentaje de los que estaban a favor triplicaba al de los que estaban en contra. Si se tiene en cuenta la radicalidad de la actitud crítica ante la UE por parte del PCE e IU y, muy especialmente, del líder de ambas formaciones, Julio Anguita, puede llegarse a la conclusión de que se estaba produciendo un significativo distanciamiento entre la dirigencia y la base social del comunismo.

Cuadro 3. Actitud ante la UE por variables políticas en 1997 (según recuerdo de voto en las elecciones de 1996)

\begin{tabular}{|l|c|c|c|}
\cline { 2 - 4 } \multicolumn{1}{c|}{} & A favor & En contra & Ni a favor ni en contra \\
\hline IU & $60,3 \%$ & $20,5 \%$ & $16,5 \%$ \\
\hline PP & $71,3 \%$ & $10,6 \%$ & $12,6 \%$ \\
\hline PSOE & $65,0 \%$ & $11,5 \%$ & $18,6 \%$ \\
\hline TOTAL & $63,7 \%$ & $12,5 \%$ & $18,5 \%$ \\
\hline
\end{tabular}

Fuente: CIS, Estudio 2246, 1997 (Szmolka, 1999: 67).

El discurso comunista sobre el proceso de integración en la coyuntura del acceso a la moneda única enfatizaba las consecuencias negativas del cumplimiento de las condiciones de convergencia considerando que la «homogeneidad monetaria» tenía «como condición la degradación social» ${ }^{16}$. Las críticas al Gobierno de Aznar por los sacrificios supuestamente impuestos a la sociedad española se extendían también al PSOE, ahora en la oposición, por su coincidencia con la política europea de la derecha. La estrategia de las «dos orillas» no solo mantenía su vigencia en el nuevo contexto político que se había abierto tras la derrota electoral del socialismo en 1996 sino que incluso se acrecentaba rechazando cualquier tipo de unidad con el PSOE:

16. Utopías. Nuestra Bandera, 175, 1998, p. 130. 
«Nosotros estamos en contra de José María Aznar no porque no nos guste su bigote o porque sea de Valladolid. Estamos en contra de José María Aznar por las políticas que hace $[\ldots]$ ¿Me entendéis por donde voy? Porque cuando dicen: «Todos unidos contra la derecha», la pregunta es: ¿y que vamos a combatir de la derecha, las privatizaciones, la Moneda Única? Y resulta que el que ha hablado está a favor de ambas cosas» (Anguita, 2014, 73 s.).

\section{Europa en la segunda crisis del comunismo español}

En el XV Congreso del PCE, celebrado en diciembre de 1998, Julio Anguita abandonó la secretaría general del PCE, pero mantuvo, por el momento, el puesto de coordinador general de IU. La línea ideológica del partido reafirmó en dicho congreso las mismas constantes que, bajo el mandato de Anguita, habían caracterizado la política europea del comunismo desde el Tratado de Maastricht. En su discurso de despedida Anguita recordó a los asistentes que «los comunistas son anticapitalistas, antisistema y se oponen al orden establecido», descalificó la socialdemocracia y reafirmo la «absoluta vigencia de las ideas comunistas» ${ }^{17}$. El abandono de Anguita se producía en un contexto crítico para el PCE e IU. En 1997 había tenido lugar la escisión parlamentaria de tres diputados de Izquierda Unida, los que formaban parte de la corriente denominada Nueva Izquierda, por su oposición a la política de enfrentamiento con el PSOE. También se habían deteriorado, por idéntico motivo, las relaciones con Comisiones Obreras (CC.OO.), el sindicato afín al PCE, a cuyo secretario general, Antonio Gutiérrez, se acusaba de plegarse a las políticas sociales del Gobierno socialista. Las encuestas de opinión del Centro de Investigaciones Sociológicas mostraban desde 1996 un descenso del respaldo electoral de IU que afectaba también a Anguita cuya valoración por la opinión pública (Vid. cuadro 2) cayó del 5,93 en 1994 al 3,40 en 1999. La prueba evidente de dicho descenso se produjo en las elecciones al Parlamento vasco celebradas en 1998 en las que IU perdió prácticamente la mitad de sus votos pasando de 6 diputados en las anteriores elecciones a solo 2 diputados.

En ese contexto de progresivo debilitamiento del comunismo se celebraron en junio de 1999 las elecciones al Parlamento europeo. En enero de ese mismo año había comenzado su andadura la Unión Monetaria Europea a la que España había accedido tras cumplir los criterios de convergencia exigidos. Aunque en el programa electoral de IU no se abogaba por una vuelta atrás que implicase el abandono por España de la nueva moneda, sí se insistía en las consecuencias perjudiciales que iban a derivarse de la implantación de la misma. Según Anguita, autor del marco general del programa, empezar una

17. El País Digital, 947, 06-12-1998.

Pasado y Memoria. Revista de Historia Contemporánea, 24, 2022, pp. 10-41 
construcción y desarrollarla únicamente a través de la Moneda Única, era en el fondo «no ir a la construcción sino al enfrentamiento de unas zonas de Europa contra otras zonas de Europa». Ante el extendido consenso europeísta en la aceptación de la moneda única, Anguita advertía sobre la contradicción en que incurrían aquellos que, en el propio espacio político e ideológico de IU, defendían la unión monetaria pero, sin embargo, contemplaban también las posibles consecuencias negativas de esta:

«Afirman que la moneda única tal y como se está construyendo ahora es un avance extraordinario, es fuente de progreso, pero al folio y medio de la intervención, empiezan a atacar las consecuencias de la moneda única. Nadie puede tener dos almas y nadie puede poner una vela a dios y otra al diablo, desde las fuerzas de izquierda y de los sindicatos menos que nadie. Es hora ya que entremos en este debate que puede ayudar. Cojamos la opción que cojamos, entremos a fondo y no engañemos a nadie. Para empezar, por honestidad intelectual, no nos engañemos a nosotros mismos» ${ }^{18}$.

Los resultados de las elecciones europeas de 1999 significaron un gran avance para los partidos del «consenso europeísta», PP y PSOE, y un descalabro electoral para IU. La formación liderada por Anguita que en las anteriores elecciones europeas había obtenido el 13,44 por 100 de los votos se desplomó al 5,77 por 100 pasando de 9 a 4 eurodiputados. Ante ese fracaso electoral, y acusando problemas de salud, Anguita cedió al nuevo secretario general del PCE, Francisco Frutos, la candidatura a la presidencia del Gobierno por IU para las elecciones legislativas de marzo del 2000 y posteriormente, en octubre de ese mismo año, abandonó también la coordinación general de IU para la que fue elegido Gaspar Llamazares.

Con la secretaría general de Francisco Frutos se abrió un largo período de declive político y electoral del PCE e IU que se prolongó hasta que los efectos de la crisis económica de 2008 comenzaron a repercutir en la opinión pública. El nuevo secretario general era hombre de confianza de Anguita e ideológicamente anclado, en principio, en posiciones de mayor radicalidad y ortodoxia comunista que su antecesor ${ }^{19}$. No obstante, ante las elecciones legislativas del año 2000 optó por un acercamiento al PSOE con el que suscribió un pacto pre-electoral de investidura, pero ese acercamiento resultó perjudicial para ambos partidos. Capitalizando ahora el efecto positivo de la entrada de

18. Archivo Histórico de los Programas Electorales de IU. Programa IU elecciones europeas de 1999, p. 6.

19. Frutos había defendido el leninismo en el IX Congreso del PCE y había tomado posición contra el eurocomunismo en el V Congreso del PSUC (Elorza, 1998). Una recopilación de sus discursos en Frutos (2009). 
España en la UME, Aznar consiguió una holgada mayoría absoluta e Izquierda Unida, opuesta a dicha entrada, perdió más del 50 por 100 de los votos y vio reducida su representación en el Congreso a 8 diputados. En las siguientes elecciones legislativas, las de 2004, el PSOE recuperó la mayoría parlamentaria e IU continuó su descenso electoral obteniendo el 4,96 por 100 de los votos y 5 diputados. Las elecciones europeas de ese mismo año supusieron un nuevo retroceso al alcanzar solo el 4,15 por 100 de los votos.

Bajo la presidencia de Rodríguez Zapatero se reforzó el consenso europeísta entre el PSOE y el PP y continuaron las reticencias del PCE/IU ante el proceso de integración. En la ratificación parlamentaria del Tratado de Niza en 2001 los diputados de IU/Iniciativa por Cataluña (IC) habían sido los únicos en no apoyar dicho tratado a pesar de los avances en unidad política que este contemplaba y de la mejora de la representación española en las instituciones comunitarias $^{20}$. Iba a ser en 2005, sin embargo, en torno al Tratado Constitucional Europeo, cuando el disenso del comunismo se hizo más explícito. El acuerdo sobre dicho tratado se había iniciado en el Consejo Europeo de Niza de diciembre de 2000 y había dado paso a una denominada Convención Europea, presidida por Giscard D'Estaing, como foro de reflexión sobre el futuro de Europa que debería culminar en una Conferencia Intergubernamental en la que se procedería a la reforma del Tratado de la UE para dar paso al nuevo tratado. La posición del PCE ante la inminente aprobación de dicho tratado abundaba en las dos líneas argumentales que, desde Maastricht, habían determinado su política europea. Una de ellas era la consideración de que el proceso de integración había institucionalizado los «principios de la economía neoliberal, con primacía del mercado, que ocasionan el desmantelamiento de los servicios públicos, reforma de las pensiones y graves recortes de los derechos sociales». La otra argumentación era la relativa al déficit democrático y se traducía en una propuesta de máximos que postulaba el inicio de un verdadero proceso constituyente:

«El PCE siempre propugnó la necesidad de redactar una Constitución para Europa. [...] No obstante nos reafirmamos, tal como se señalaba en el año 1989, en la necesidad para ello de proceder a la apertura de un período constituyente que, coincidiendo con la nueva legislatura, posibilite la constitución de un espacio político de democracia avanzada, en el que las competencias constituyentes residan de modo principal en el Parlamento europeo» ${ }^{21}$.

20. Los argumentos para la abstención en: DSC, $n^{\circ}{ }^{\circ} 111,04-10-2001$, pp. 5416-5418.

21. Resolución del Comité Federal del PCE sobre la construcción europea. Utopías. Nuestra Bandera, 198, 2003, p. 4. 
La aprobación del Tratado Constitucional en la cumbre de jefes de Estado y de Gobierno de los veinticinco países europeos celebrada en Roma el 24 de octubre de 2004 abría el período de ratificación de todos y cada uno de los Estados miembros durante los dos años siguientes. En el caso de España esa ratificación se produjo mediante un referéndum previo, de carácter consultivo, convocado por el Gobierno de Zapatero para el 20 de febrero de 2005. A diferencia de otros países de la Unión, la actitud favorable de la ciudadanía española respecto a los beneficios de la pertenencia a la UE había aumentado extraordinariamente desde finales de siglo (Vid. gráfico 1) en coincidencia con la incorporación del país a la UME. La política europea de Zapatero, plenamente identificada con el eje franco-alemán, trasmitía a la opinión pública una creciente confianza en las virtudes de un proceso comunitario que, supuestamente, iba a alcanzar un nuevo hito con la aprobación del nuevo tratado. El referéndum podía servir también, así pues, para reforzar el liderazgo del nuevo presidente del Gobierno.

La mayoría de las fuerzas políticas españolas, aunque con distintos matices, pidieron el voto afirmativo lo que significaba el mantenimiento del consenso europeísta, especialmente entre los dos partidos mayoritarios, PSOE y PP (Ramiro y Morales, 2007: 139). Tanto el PCE como IU asumieron una posición crítica ante el tratado solicitando el voto contrario por la «falta de un proceso constituyente y su retraso respecto a las aspiraciones sociales y pacifistas de la ciudadanía $»^{22}$. Otra de las motivaciones del rechazo era la falta de reconocimiento de un modelo federal y de los pueblos en Europa, objeción planteada también por Esquerra Republicana y otros partidos nacionalistas del ámbito catalán y vasco que solicitaron el voto negativo.

Los resultados del referéndum dieron un rotundo triunfo al Sí $(81,84 \%)$ y un más que modesto apoyo al NO $(18,16 \%)$. Si se tiene en cuenta que las circunscripciones donde se registró un menor respaldo fueron las catalanas y las vascas (menos del 70\% de votos afirmativos), en las que el nacionalismo más radical había solicitado también el voto negativo, puede deducirse la escasa repercusión en la opinión pública del llamamiento al NO por parte del PCE/ IU. Si se desciende al análisis del voto por proximidad partidista (Vid. cuadros 4 y 5) puede observarse que incluso entre los electores de IU hubo un alto porcentaje que no siguió las indicaciones de dicha formación política. Resulta también relevante que la valoración favorable del Tratado Constitucional y de la UE por parte de dicho electorado superase los porcentajes de la valoración desfavorable, con la única excepción de la imagen de las Instituciones europeas,

22. Declaraciones de Llamazares a la Agencia EFE (https://www.libertaddigital.com/nacional/iu-hara-causa-comun-con-erc-para-pedir-el-voto-en-contra-de-la-constitucioneuropea-1276229170/) 
pero solo por un ligero margen: 46 por 100 favorable frente al 50 por 100 desfavorable.

Cuadro 4. Votación en el referéndum de 2005 sobre el Tratado Constitucional por proximidad partidista

\begin{tabular}{|l|c|c|c|c|}
\cline { 2 - 5 } \multicolumn{1}{c|}{} & Abstención & Sí & No & En blanco \\
\hline PP & $57 \%$ & $72 \%$ & $19 \%$ & $8 \%$ \\
\hline PSOE & $42 \%$ & $93 \%$ & $4 \%$ & $2 \%$ \\
\hline IU & $52 \%$ & $32 \%$ & $61 \%$ & $6 \%$ \\
\hline $\begin{array}{l}\text { TOTAL DE } \\
\text { ENCUESTADOS }\end{array}$ & $58 \%$ & $75 \%$ & $17 \%$ & $6 \%$ \\
\hline
\end{tabular}

Fuente: La Constitución Europea: encuesta post-referéndum en España, Flash Eurobarómetro, marzo de 2005 (La suma de Sí, No y En blanco no se ajusta exactamente al 100\% debido a un pequeño porcentaje de No sabe/No contesta).

Cuadro 5. Valoración de la Constitución Europea y de la UE por proximidad partidista al PSOE e IU

\begin{tabular}{|l|c|c|c|c|c|c|}
\cline { 2 - 7 } \multicolumn{1}{c|}{} & \multicolumn{2}{c|}{$\begin{array}{c}\text { De } \\
\text { acuerdo }\end{array}$} & \multicolumn{2}{c|}{ En desacuerdo } & \multicolumn{2}{c|}{$\begin{array}{c}\text { No sabe / } \\
\text { No contesta }\end{array}$} \\
\hline & PSOE & IU & PSOE & IU & PSOE & IU \\
\hline $\begin{array}{l}\text { Buena imagen de las } \\
\text { Instituciones de la UE }\end{array}$ & $76 \%$ & $46 \%$ & $16 \%$ & $50 \%$ & $8 \%$ & $4 \%$ \\
\hline $\begin{array}{l}\text { La Constitución hará más } \\
\text { fuerte a España en el seno de } \\
\text { la UE }\end{array}$ & $82 \%$ & $48 \%$ & $11 \%$ & $40 \%$ & $7 \%$ & $12 \%$ \\
\hline $\begin{array}{l}\text { La Constitución Europea } \\
\text { refuerza la democracia }\end{array}$ & $83 \%$ & $49 \%$ & $9 \%$ & $47 \%$ & $8 \%$ & $4 \%$ \\
\hline $\begin{array}{l}\text { La Constitución es } \\
\text { indispensable para proseguir } \\
\text { la construcción europea }\end{array}$ & $82 \%$ & $50 \%$ & $10 \%$ & $48 \%$ & $8 \%$ & $2 \%$ \\
\hline $\begin{array}{l}\text { Para España ser miembro de la } \\
\text { UE es algo bueno }\end{array}$ & $91 \%$ & $74 \%$ & $4 \%$ & $22 \%$ & $5 \%$ & $4 \%$ \\
\hline
\end{tabular}

Fuente: La Constitución Europea: encuesta post-referéndum...

Pocos meses después del referéndum español se celebraron los referendos de Francia y Holanda en los que el electorado de ambos países rechazó la ratificación dando así al traste con el proyecto de Tratado Constitucional. Una explicación del distinto comportamiento de la opinión pública en España y en 
estos otros dos países remite, sin duda, a la distinta situación política, económica y social por la que atravesaban. Prácticamente todos los análisis y estudios sobre los resultados de los referendos en Francia y Holanda coincidían en que era el «contexto»y no el «texto» lo que había motivado el rechazo. Distintos factores ligados al deterioro de las prestaciones sociales, la inmigración, el rebrote de un nacionalismo económico o el distanciamiento entre ciudanía y élites políticas eran los que explicaban el NO al Tratado Constitucional (Forner, 2009: 103 ss.). Un caso contrario era el de España donde se estaba produciendo una evolución económica al alza y el mantenimiento desde el año 2000 de una reducida tasa de paro que entre 2005 y 2007 registró niveles inferiores al 9 por 100, cifra desconocida desde el año 1978. La cohesión económica y social se estaba materializando mediante los fondos «Delors 2» y la «Agenda 2000» que entre 1994 y 2006 habían supuesto un total de más de 90.000 millones de euros. Por primera vez desde 1974 las cuentas públicas se saldaron con superávit en 2005, 2006 y 2007, debido fundamentalmente a un extraordinario aumento de la recaudación que permitió también al Gobierno de Rodríguez Zapatero incrementar el gasto público de carácter social.

Las elecciones legislativas de marzo de 2008 dieron de nuevo una mayoría al PSOE, que aumentó su porcentaje de voto, al igual que el PP. Entre ambos partidos obtuvieron 323 diputados de un total de 350. Izquierda Unida, por el contrario, se desplomó al 3,77 por 100, el porcentaje más bajo, por el momento, de toda su historia con una representación en el Congreso de tan solo dos diputados. Meses después se produjo la ratificación parlamentaria del Tratado de Lisboa, con el que se había resuelto la crisis institucional de la UE motivada por el fracaso del Tratado Constitucional. La posición de IU sobre el nuevo tratado continuó basándose en los mismos argumentos esgrimidos contra el Tratado Constitucional. En el debate parlamentario celebrado en junio de 2008, Gaspar Llamazares siguió insistiendo en la esencia neoliberal del texto y la configuración de una «Europa exclusivamente económica, de la división y de la exclusión social ${ }^{23}$. La IX Asamblea Federal de Izquierda Unida, celebrada en noviembre de 2008, reafirmó el rechazo al Tratado de Lisboa considerándolo un paso más en el «modelo europeo surgido de los tratados constitutivos de las Comunidades europeas» sostenido en «criterios neoliberales». En el apoyo a ese modelo coincidían, según Izquierda Unida, el PP y el PSOE, es decir, reverdecía la antigua estrategia de «las dos orillas» auspiciada por Anguita durante la década de 1990:

23. DSC, $n^{\circ}{ }^{\circ} 20,26-06-2008$, pp. 19-21. 
«La realidad política española se caracteriza al menos por dos elementos: por una parte la presencia fuerte y activa de una derecha que no oculta su ideología conservadora [...] La otra, un social-liberalismo que implementa desde hace tiempo un liberalismo social que, cada vez más, significa una ruptura con las políticas reformistas y que se configura como el ala social del proyecto neoliberal dominante. Ambas realidades son efecto y causa de un modelo de integración europea que está degradando los derechos democráticos, convirtiéndose en la excusa para ir destruyendo los derechos sociales y laborales en todo el continente e impidiendo de hecho estrategias económicas y sociales alternativas al modelo neoliberal $»^{24}$.

El discurso contrario a la «Europa neoliberal» se mantuvo en el programa electoral de IU para las elecciones europeas de junio de 2009. En esa fecha habían ya asomado los primeros síntomas de la crisis financiera internacional, interpretada por IU como una crisis del capitalismo que suponía el «fracaso de la globalización neoliberal» y «la desarticulación del Estado de Bienestar». Esa crisis cuestionaba, según IU, los fundamentos del propio proceso comunitario al haberse basado este en «una economía de mercado abierta con libre competencia ${ }^{25}$. La asociación entre la crisis y la naturaleza del proceso de integración podía hacer más receptivo en la opinión pública española el discurso crítico sobre la Unión Europea mantenido desde Maastricht, pero los resultados de las elecciones europeas no pudieron ser, sin embargo, más decepcionantes. Con un 3,71 por 100 de los votos, IU obtenía el respaldo electoral más bajo de toda su historia en unas elecciones de ámbito nacional, empeorando incluso el de las elecciones legislativas del año anterior. Por el contrario, los partidos del «consenso europeísta», PSOE y PP, mantenían su alto respaldo electoral sumando entre ambos más del 80 por 100 de los votos emitidos. Las elecciones europeas de 2009 mostraban también un cambio de tendencia hacia la derecha que se traducía en el triunfo de la candidatura del PP encabezada por Mayor Oreja. En las elecciones legislativas de 2011, y en plena crisis económica, el PP obtuvo la mayoría absoluta sin que la materialización en cierta forma de los augurios críticos sobre el euro mantenidos durante largos años, fuera capitalizada de forma muy significativa por IU en el campo de la izquierda a pesar del enorme retroceso electoral del PSOE en dichas elecciones.

24. IX Asamblea Federal de IU. Utopías. Nuestra Bandera, $n^{\circ}{ }^{2} 222,2009$, p. 104.

25. Archivo Histórico de los Programas Electorales de IU. Programa IU elecciones europeas de 2009. 


\section{Conclusiones y epílogo}

Durante la segunda mitad de la década de 1980 se produjo una recuperación electoral del comunismo español, bajo la fórmula de Izquierda Unida, que coincidió con un aumento de la actitud favorable de la opinión pública hacía la Comunidad europea. Durante dichos años, el PCE reforzó su europeísmo, atenuó su anti-atlantismo e inició un proceso de «occidentalización», en sintonía con la nueva situación internacional propiciada por las reformas de Gorbachov y muy coincidente con la evolución política del Partido Comunista Italiano. La aprobación del Tratado de Maastricht originó un viraje en dicha evolución observándose desde entonces una estrecha correlación entre el aumento o disminución de sus votos y la evolución de la opinión pública sobre la integración europea.

El discurso contrario a la Europa de Maastricht coincidió con un auge de Izquierda Unida que alcanzó su máximo a mediados de la década de 1990, años en los que se produjo un significativo descenso en el apoyo de la opinión pública a la recién creada Unión Europea. El mantenimiento de dicho discurso desde finales de los noventa coincidió, por el contrario, con un declive electoral que se prolongó hasta las elecciones legislativas y europeas de 2009 en paralelo a la etapa de mayor apoyo público al proceso de integración y a la moneda única. La correlación entre la evolución del apoyo público a la UE con el auge y el declive del PCE/IU puede explicarse también, no obstante, por el efecto de las consecuencias económicas y sociales del proceso de integración y su percepción por la opinión pública. Como se ha ido viendo en las páginas de este trabajo, y puede corroborarse con los datos del gráfico $\mathrm{n}{ }^{\circ}{ }^{\circ}$, esas consecuencias estuvieron estrechamente correlacionadas, desde Maastricht, con la evolución del voto a IU. Resulta quizá por ello más verosímil considerar que ese fue el factor más relevante para explicar conjuntamente la evolución del apoyo público a la UE y del respaldo electoral de IU. En todo caso, puede concluirse que, bien de forma directa o bien por sus consecuencias sociales y económicas en el ámbito nacional, la europeización de la política española influyó decisivamente en el auge y declive del comunismo. 
Gráfico 2. Voto a IU en elecciones legislativas (L) y europeas (E) y tasa de paro

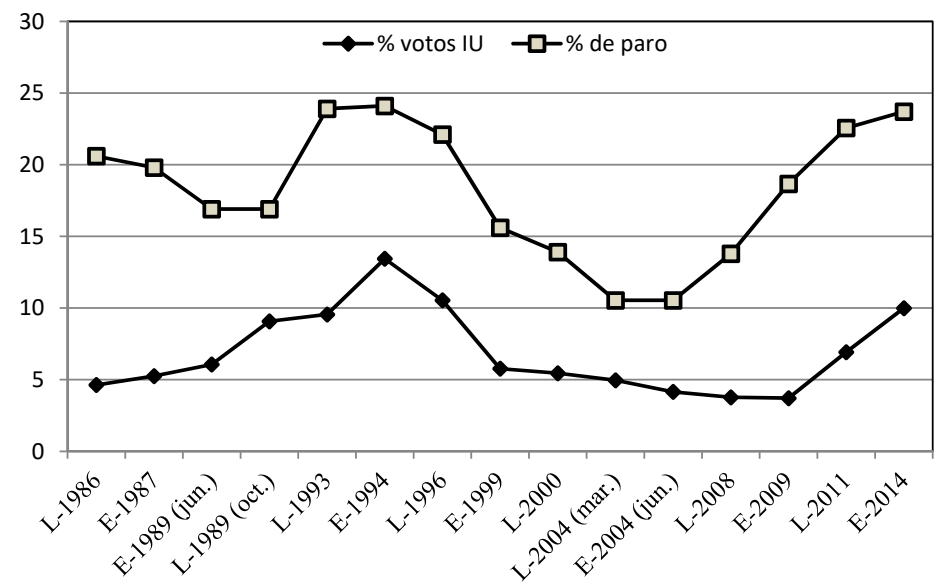

Fuente: Instituto Nacional de Estadística (elaboración propia).

Una segunda conclusión nos remite al giro anti-Maastricht efectuado por el PCE que dio paso a la denuncia de la «Europa neoliberal», mantenida desde entonces en el discurso político del comunismo español. Tras el apoyo al Tratado de Adhesión, el PCE había apoyado también el Acta Única Europea valorando favorablemente sus avances en integración económica, la introducción de la «cohesión económico-social» y las previsiones sobre una futura unificación monetaria. El Tratado de Maastricht suponía un avance mayor hacia metas de unidad económica y política, con un proyecto monetario de carácter supranacional de gran calado que abría la posibilidad de una competencia internacional con el dólar. Establecía también mecanismos de cooperación en justicia e interior y en política exterior y de seguridad, además del importante logro de la ciudadanía europea. El rechazo al Tratado de la UE resultaba, así pues, contradictorio con su aspiración a una unidad política de Europa y a una autonomía respecto a la potencia norteamericana.

Era particularmente la moneda única la que fundamentaba la oposición al denominado modelo de integración de Maastricht. El proyecto de unión monetaria era descalificado con trazos gruesos como una estrategia del «globalismo neoliberal» auspiciado por EE. UU. y como algo opuesto a la unidad política de Europa. La Unión Monetaria tenía mucho más que ver, sin embargo, con los designios constructivistas de Jacques Delors por el supuesto efecto inducido que la moneda única podía provocar precisamente para la unidad política de 
Europa. Otras razones derivadas de la debilidad del franco frente al marco, la crisis del Sistema Monetario Europeo o la reunificación alemana explicaban la configuración final de la Unión Monetaria tal como se plasmó en el Tratado de Maastricht. Por lo demás, la moneda única cumplía el viejo sueño de De Gaulle de intentar acabar con la hegemonía monetaria de Estados Unidos y no fue ni ha sido hasta el momento un proyecto bien valorado en los círculos económicos del liberalismo europeo ${ }^{26} \mathrm{ni}$ en la literatura económica anglosajona (Friedman, 1997; Krugman, 2012; Stiglitz, 2016)

¿Fue el Tratado de Maastricht el desencadenante del viraje ideológico y estratégico del PCE respecto a la integración europea? Dada la evolución posterior de la política europea del comunismo, más bien podría decirse que Maastricht fue solo el pretexto para superar el dilema que suponía el apoyo a la integración europea y el mantenimiento de la ideología anticapitalista como seña de identidad diferenciadora de la socialdemocracia. Ese dilema podía resolverse mediante la «vía italiana», opción planteada por sectores minoritarios del PCE e IU para la transformación del PCE en una nueva formación política, o abandonando, como así ocurrió bajo el mandato de Anguita, el bucle europeísta en el que el PCE había permanecido desde la transición democrática junto al PCI y en contraposición al resto de partidos comunistas europeos.

Con el tiempo, el discurso contrario a Maastricht se deslizó, retrospectivamente, a la completa oposición al proceso de integración desde sus orígenes por su naturaleza plenamente capitalista. Dicha evolución se enmarcaba en una vuelta a las señas de identidad tradicionales del comunismo que incardinaba de nuevo plenamente al PCE en el movimiento comunista internacional y lo acercaba al emergente «neocomunismo» bolivariano del espacio latinoamericano. En el caso de la actitud ante Europa, ese viraje supuso el restablecimiento de la coincidencia con partidos como el francés, el portugués y el griego que, en todo momento, se habían opuesto al proceso de integración. Se trataba, en definitiva, de una vuelta al anti-europeísmo ideológico mantenido por el PCE hasta la década de 1970.

Desde la Ciencia Política se ha acuñado el término «euroescepticismo», en sus versiones hard o soft, para englobar al conjunto de formaciones políticas con posiciones críticas ante el proceso de integración, como sería el caso del PCE (Gómez-Reino, Llamazares, y Ramiro, 2008: 136 ss.). Cabría preguntarse, sin embargo, si su adjetivación como partido euroescéptico en su versión soft sigue siendo la adecuada para definir la trayectoria de la política

26. Para el caso de España pueden verse las posiciones liberales contrarias a la moneda única en: La moneda única, entre el dogma y el debate. Soluciones. Cuadernos de Economía de Mercado, $n .^{\circ} 2,1996$. 
europea del comunismo español, especialmente tras la crisis de $2008^{27}$. Es cierto que el PCE e IU han venido abogando por un proceso constituyente europeo mediante la elección de una Asamblea Constituyente para aprobar una Constitución Europea que otorgue al Parlamento europeo todas las competencias legislativas ${ }^{28}$. Esa propuesta de máximos no deja de ser, sin embargo, por su inviabilidad, un «brindis al sol» con el que revestir de europeísmo la oposición frontal a la integración europea «realmente existente», basada desde sus inicios, efectivamente, en favorecer el desarrollo del capitalismo y en la lógica del mercado.

La oposición a la UE, derivada del anti-europeísmo ideológico, no se correspondió desde mediados de la década de 1990, como ha podido verse, con el estado de una opinión pública muy identificada con el proceso de integración y con la moneda única, y ello contribuyó al prolongado declive electoral de IU hasta las elecciones de 2011. En dichas elecciones, con la candidatura del nuevo coordinador general, Cayo Lara, Izquierda Unida inició una recuperación electoral con un aumento de su porcentaje de voto hasta cerca del 7 por 100 , pasando de 2 a 11 escaños. La crisis favorecía un clima de mayor desconfianza hacia la UE por parte de la opinión pública y un deterioro económico de los que parecía beneficiarse electoralmente Izquierda Unida.

Las tesis sobre Europa aprobadas en el XIX Congreso del PCE, celebrado en noviembre de 2013, reforzaron la posición contraria a la integración, considerada como un proceso que supedita «los intereses de los pueblos de Europa a los intereses de sus oligarquías económicas ${ }^{29}$. Las elecciones europeas de 2014 , celebradas en coincidencia con el mayor aumento del paro tras la crisis (Aixalà i Blanch, 2014: 44 ss.) dieron un nuevo impulso electoral a IU que obtuvo algo más del 10 por 100 de los votos, subiendo de 2 a 6 eurodiputados. Se trataba, sin embargo, de un «canto de cisne» electoral. Una nueva formación política, Podemos, surgida del «movimiento de indignados» y con un programa igualmente crítico frente a la UE y el euro, emergía con fuerza obteniendo 5 eurodiputados.

En las elecciones legislativas de 2015 Podemos, configurada como una opción anti-sistema, logró captar prácticamente todo el voto del descontento social y político de la ciudadanía (Teruel, Barrio y Barberá, 2018: 217-224)

27. Una crítica del euroescepticismo como categoría poco consistente y con escaso valor heurístico para englobar las distintas oposiciones a la UE en Holmes y Roder (2012).

28. IX Asamblea Federal de IU. Utopías. Nuestra Bandera, $n .^{\circ}$ 222, 2009, p. 109.

29. XIX Congreso del PCE, Madrid 15, 16 y 17 noviembre de 2013. Tesis Políticas. Partido Comunista de España (http://2001-2018.pce.es/descarga/20131115_17_docpce_xix_ cong_tesis_politicas_def.pdf). 
obteniendo más de cinco millones de votos y 69 diputados. La vieja aspiración de Anguita al sorpasso del PSOE desde la izquierda se hacía por primera vez verosímil pero no era Izquierda Unida quien la protagonizaba. Con solo el 3,6 por 100 de votos, el porcentaje más bajo de toda su historia, y solo dos diputados, Izquierda Unida y el PCE quedaron eclipsados por Podemos e inmersos en una aguda crisis. Posteriormente confluyeron en una alianza electoral con la nueva formación política ocupando en la misma una posición muy marginal y subordinada.

\section{Bibliografía}

AIXALÀ I BLANCH, Albert (2014). Crisis económica y euroescepticismo (20072014). Barcelona: Fundación Alternativas.

ALBARRACÍN, Jesús y MONTES, Pedro (1992). El sueño liberal engendra monstruos. La Europa de Maastricht y la convergencia española. En MARTIN SECO, Juan Francisco et (al). La izquierda y Europa. Una aproximación crítica al Tratado de Maastricht (55-108). Madrid: Los Libros de la Catarata.

ANDERSON, Christopher (1998). When in Doubt, Use Proxies: Attitudes toward Domestic Politics and Support for European Integration. Comparative Political Studies, 31(5), 569-601.

ANGUITA, Julio (1990). Izquierda Unida: la apuesta de los comunistas españoles. Nuestra Bandera, 140, 4-13.

ANGUITA, Julio (2014). ¡Rebelión! Murcia: Alfaqueque Ediciones.

ANGUITA, Julio y MONEDERO, Juan Carlos (2013). A la izquierda de lo posible. Madrid: Icaria.

ANGUITA, Julio y ANDRADE, Juan (2015). Atraco a la memoria. Un recorrido histórico por la vida política de Julio Anguita. Madrid: Akal.

ANGUITA, Julio y FLOR, Julio (2017). Contra la ceguera: cuarenta años luchando por la utopía. Madrid: La esfera de los libros.

AVILÉS, Juan (2004). España y la integración europea: partidos y opinión pública, 1977-2004. Espacio, Tiempo y Forma, 16, 409-423.

BELL, David (1996). Western Communist Parties and the European Union. En John GAFFNEY. Political Parties and European Union (220-234). Londres: Routledge.

BOSCO, Anna y GASPAR, Carlos (2001). Four Actors in Search of a Role. The Southern European Communist Parties. En P. Nikiforos DIAMANDOUROS y Richard GUNTHER. Parties, Politics, and Democracy in the Southern European Communist Parties (329-387). Baltimore: JHU Press.

CONWAY, Martin y PATEL, K. Klaus (2010). Europeanization in the Twentieth Century, Historical Approaches. Basingstoke: Palgrave. 
COTTA, Maurizio; ISERNIA Pierangelo; VERZICHELLI, Luca (2005). L'Europa in Italia, Élite, opinione pubblica e decisioni. Bolonia: Il Mulino.

COTTA, Maurizio (2005). Élite, politiche nazionali e costruzione della policy europea. Il caso italiano in prospettiva comparata. En COTTA, Maurizio; ISERNIA Pierangelo; VERZICHELLI, Luca. L'Europa in Italia, Élite, opinione pubblica e decisioni (17-59) Bolonia: Il Mulino.

ELORZA, Antonio (1998). Llega un leninista. El País, 26-06-1998.

FORNER, S. (2009). Proyecto europeo y opinión pública: las raíces de un creciente desencuentro. Historia y Política, 21, 95-115.

FORNER, S. y SENANTE (2015). La crisis del comunismo en Europa occidental: entre el eurocomunismo y el colapso del bloque soviético. Historia y Política, 33, 303-331.

FORNER, S. y SENANTE (2019). La política europea del PCE (1972-1999): del viraje europeísta al euroescepticismo. Historia y Política, 41, 335-366.

FRIEDMAN, Milton (1997). The Euro: Monetary Unity to Political Disunity? Project Syndicate (https://www.project-syndicate.org/commentary/the-euro-monetary-unity-to-political-disunity? barrier=accesspaylog).

FRUTOS, Francisco (2009) La experiencia dialéctica del Secretario General del Partido Comunista de España: Discursos de Francisco Frutos Gras. Nuestra Bandera, 221, vol. III.

GÓMEZ-REINO, M., LLAMAZARES, I., y RAMIRO, L. (2008). Euroscepticism and Political Parties in Spain. En SZCZERBIAK y TAGGART. Opposing Europe, vol. 1, (134-151). Oxford: Oxford University Press.

GRANDE, Edgar y HUTTER, Swen (2016). Is the giant still asleep? The politicisation of Europe in the national electoral arena. En Swen HUTTER, Edgar GRANDE y Hanspeter KRIESI. Politicising Europe. Integration and Mass Politics. Cambridge: Cambridge University Press.

HEYWOOD, Paul (1994). The Spanish Left: Towards a Common Home? En Martín J. BULL y Paul HEYWOOD. West European Communist Parties after the Revolutions of 1989. Nueva York: St. Martin's Press.

HOLMES, Michael y RODER, Knut (2012). The left and the European Constitution. From Laeken to Lisbon. Manchester: Manchester University Press.

IGLESIAS, Gerardo (1984). La opción comunista, hoy (57-70). En España, hoy. Madrid: Unión Editorial.

IGLESIAS, Gerardo (1986). Europa: autonomía o decadencia. Nuestra Bandera, 133, 5-7.

KRUGMAN, Paul (2012). ¡Acabad ya con esta crisis! Barcelona: Crítica.

MARKS, Gary; WILSON, Carole; RAY, Leonard (2002). National Political Parties and Europea Integration. American Journal of Political Science, 46, 3, 585-594. 
MARTÍN SECO, Juan Francisco (1992). El desequilibrio europeo. En MARTIN SECO, Juan Francisco et (al). La izquierda y Europa. Una aproximación crítica al Tratado de Maastricht (11-21). Madrid: Los Libros de la Catarata.

MATEOS, Abdón (2016). Los socialistas españoles y la cuestión atlántica. Ayer, 103, 51-70.

MONEREO, Manuel (2010). La crisis de la Unión Europea y Julio Anguita. http:// www.rebelion.org/noticia.php?id=101647.

OLSEN, Johan P. (2002). The Many Faces of Europeanization. Journal of Common Market Studies, v. 40, 5, 921-952.

PALERO, Francisco (1990). Europa unida: un proyecto posible. Nuestra Bandera, $145,40-47$.

RAMIRO, Luis y MORALES, Laura (2007). European Integration and Spanish Parties. En Thomas POGUNTKE et al. National Political Parties. Power and Organizational Adaptation. Londres: Routledge.

RAY, Leonard (2003). When Parties Matter: The Conditional Influence of Party Positions on Voter Opinions about European Integration. The Journal of Politics, Vol. 65, No. 4, pp. 978-994.

STIGLITZ, Joseph (2016). El euro. Cómo la moneda común amenaza el futuro de Europa. Barcelona: Taurus.

SZMOLKA, Inmaculada (1999). Opiniones y actitudes de los españoles ante el proceso de integración europea. Madrid: Centro de Investigaciones Sociológicas.

TERUEL, J. R., BARRIO, A. y BARBERÁ, O. (2018). Podemos: de partido anticasta a confluencia de la plurinacionalidad. En Francisco J. LLERA et alii. Las elecciones generales de 2015 y 2016. Madrid: CIS.

TREGLIA, Emanuele (2019). Contra el nuevo orden mundial. El comunismo español ante la posguerra fría. Pasado y Memoria. Revista de Historia Contemporánea, 19, 127-155.

VÁZQUEZ-GARCÍA, Rafael (2012). The Spanish Party System and European Integration - a Consensual Europeanisation. En Erol KÜLAHCI. Europeanisation and Party Politics. Colchester: ECPR Press. 